\title{
Ischemic stroke risk estimation in patients without oral anticoagulation: an observational cohort study based on secondary data from Germany
}

Felix S. Wicke ${ }^{1 *}$ (D, Martin A. Schaller ${ }^{2}$, Kateryna Karymova ${ }^{1}$, Martin Beyer ${ }^{1}$ and Beate S. Müller ${ }^{1}$

\begin{abstract}
Background: Oral anticoagulants can cause potentially serious adverse events. Therefore, before prescribing oral anticoagulants for ischemic stroke prevention in patients with atrial fibrillation (AF), stroke risk assessment is required to identify patients that are likely to benefit from treatment. Current guidelines recommend the $\mathrm{CHA}_{2} \mathrm{DS}_{2}$ VASc-score for stroke risk assessment. The $\mathrm{CHA}_{2} \mathrm{DS}_{2}$-VASc-score is based on observational studies from different treatment settings and countries. As ischemic stroke risk differs by setting and region, the aim of this study is to estimate ischemic stroke risk (stratified by the $\mathrm{CHA}_{2} \mathrm{DS}_{2}-\mathrm{VASc}$-score) for a broadly representative population with $\mathrm{AF}$ from southern Germany and compare them to results from previous studies.

Methods: The study design is a retrospective cohort study on patients with atrial fibrillation based on secondary data. We calculated $\mathrm{CHA}_{2} \mathrm{DS}_{2}$-VASc-score based on patient's diagnoses recorded in the year 2014 and assessed outcomes in 2015-2016. The primary outcome is hospitalization for ischemic stroke. The secondary outome is hospitalizations for any thromboembolic event, including ischemic stroke, transient ischemic attack, peripheral arterial embolism, pulmonary embolism, and mesenterial embolism. We estimated the incidence rates of the outcomes (and corresponding 95\%-confidence intervals) stratified by $\mathrm{CHA}_{2} \mathrm{DS}_{2}-\mathrm{VASc}$-score.
\end{abstract}

Results: The primary endpoint occurred in 961 of the 30,299 patients constituting the study population, resulting in a total incidence rate of 2.2 per 100 person-years. The secondary endpoint occurred in 1553 patients (3.6 per 100 person-years). Ischemic stroke rates stratified by the $\mathrm{CHA}_{2} \mathrm{DS}_{2}$-VASc-score tended to be lower than those reported previously. Thromboembolic event rates stratified tended to be similar to those reported previously.

Conclusions: Our results show that the performance of the $\mathrm{CHA}_{2} \mathrm{DS}_{2}-\mathrm{VASc}-\mathrm{score}$ differs in the German population, as compared to internationally published data, with an overall trend towards lower risk of ischemic stroke in uncoagulated patients with AF. These results should not be practice changing, but they emphasize that stroke risk estimation in patients with atrial fibrillation should be further refined.

Keywords: Atrial fibrillation, Stroke, Ischemia, $\mathrm{CHA}_{2} \mathrm{DS}_{2}$-VASc-score, Anticoagulation, Risk assessment, Cardiovascular epidemiology, Incidence rate

\footnotetext{
*Correspondence: wicke@allgemeinmedizin.uni-frankfurt.de

${ }^{1}$ Institute of General Practice, Goethe-University, Theodor-Stern-Kai 7, 60590

Frankfurt, Germany

Full list of author information is available at the end of the article
}

(c) The Author(s). 2019 Open Access This article is distributed under the terms of the Creative Commons Attribution 4.0 International License (http://creativecommons.org/licenses/by/4.0/), which permits unrestricted use, distribution, and reproduction in any medium, provided you give appropriate credit to the original author(s) and the source, provide a link to the Creative Commons license, and indicate if changes were made. The Creative Commons Public Domain Dedication waiver (http://creativecommons.org/publicdomain/zero/1.0/) applies to the data made available in this article, unless otherwise stated. 


\section{Background}

Results from randomized controlled trials (RCTs) clearly demonstrate the benefits of oral anticoagulation in patients with atrial fibrillation (AF) [1, 2]. Whereas most patients are likely to benefit from oral anticoagulation by prevention of ischemic strokes, some patients will suffer from bleeding complications due to anticoagulation. Treatment with oral anticoagulants therefore requires a careful risk-benefit assessment.

Evidence-based estimates that help to identify which patients are more likely to suffer from bleeding events than to benefit from prevention of thromboembolism are needed. Results from randomized and controlled trials (RCTs) would be ideal, because they are not prone to confounding by indication or other biases. However, available RCTs are not powered to identify valid high- or low-risk characteristics; instead, observational studies are used to identify such characteristics. Guidelines recommend ischemic stroke risk assessment based on the $\mathrm{CHA}_{2} \mathrm{DS}_{2}$-VASc-score [3-5]. Current guideline recommendations are to start oral anticoagulation for men with a score of 2 or higher and for women with a score of 3 or higher, if there is no excessively high bleeding risk. Oral anticoagulation should be considered for male patients with $\mathrm{CHA}_{2} \mathrm{DS}_{2}$-VASc-score of 1 and for female patients with a score of 2 [3-5].

Multiple observational studies have been conducted to estimate risk of thromboembolism stratified by the $\mathrm{CHA}_{2} \mathrm{DS}_{2}$-VASc-score in patients with uncoagulated $\mathrm{AF}$ [6-12]. These studies have differed in the population they included: some used specific trial populations and others used inpatient registries or national databases. As patients from different levels of care (eg. general practice versus specialist care) are likely to differ in their risk for ischemic events, the selected population is of great importance for generalizability and interpretation. Accordingly, a systematic review of the topic reported wide variation in incidence rates of ischemic stroke in patients with $\mathrm{AF}$ [13].

Clinical implications for the use of the $\mathrm{CHA}_{2} \mathrm{DS}_{2^{--}}$ VASc-score would potentially arise, if incidence rates can be shown to differ not only between levels of care, but also geographically (e.g. between countries). To our knowledge, no study reported data for ischemic stroke risk prediction for patients with AF from Germany. Therefore, the aim of this study is to estimate ischemic stroke risk (stratified by the $\mathrm{CHA}_{2} \mathrm{DS}_{2}$-VASc-Score) for a broadly representative population with $\mathrm{AF}$ from southern Germany.

\section{Methods}

\section{Study design}

This is a retrospective cohort study with a two-year observation period (2015-2016) on patients with AF based on secondary data.

\section{Data source}

Claims data from a statutory health insurance (AOK Baden Wuerttemberg), the largest insurance fund in the German state of Baden-Wuerttemberg (population in 2014 was 10.7 million), were used. For the year 2014, the data contains information on 3.8 million individuals, which equals to about $35 \%$ of the state's population. The dataset contains information on all insured persons, including age, sex, hospital and outpatient treatments with respective diagnoses (coded according to the International Classification of Disease Version 10, ICD-10), and all outpatient drug prescriptions (coded according to the Anatomical-Therapeutic-Chemical Classification, ATC).

\section{Study population}

From the total dataset we identified all patients aged 18 years or older with a diagnosis of AF recorded in 2014. To increase diagnostic specificity, we required outpatient diagnoses to be coded in at least two quarters of the year 2014. For hospital diagnoses, only one coding was required. We excluded patients with coded rheumatic mitral valve disease or artificial heart valves and those that died in 2014. The study cohort consists of all patients with AF and without oral anticoagulation in 2014. We identified oral anticoagulants based on ATC codes of prescription data, including vitamin $\mathrm{K}$ antagonists (ATC: B01AA), direct factor Xa inhibitors (B01AF) and Dabigatran (B01AE07).

\section{Variables}

We used ICD-10 coded diagnoses of the year 2014 for the calculation of the $\mathrm{CHA}_{2} \mathrm{DS}_{2}$-VASc-score. In- and outpatient diagnoses were used and the $\mathrm{CHA}_{2} \mathrm{DS}_{2^{--}}$ VASc-score was calculated as described in Table 1.

For the outcome assessment we recorded all hospitalizations for ischemic stroke, further thromboembolic events (peripheral emboli, pulmonary emboli and transient ischemic attack) and deaths in 2015 and 2016 (ICD codes see below). To exclude the possibility that a

\begin{tabular}{|c|c|c|}
\hline & Risk Factor & Points \\
\hline C & Congestive heart failure & 1 \\
\hline $\mathrm{H}$ & Hypertension & 1 \\
\hline$A_{2}$ & Age $\geq 75$ years & 2 \\
\hline D & Diabetes mellitus & 1 \\
\hline $\mathrm{S}_{2}$ & Prior Stroke or transient ischemic attac & 2 \\
\hline V & Vascular disease & 1 \\
\hline A & Age 65 to 74 years & 1 \\
\hline \multirow[t]{2}{*}{ Sc } & Sex category (female) & 1 \\
\hline & Range of possible scores & 0 to 9 \\
\hline
\end{tabular}


diagnosis of AF was related to an acute ischemic event, we used a 'blanking period' of 14 days (as suggested by Friberg and colleagues [7]) between baseline and follow-up assessment.

The primary outcome was hospitalization for ischemic stroke. We recorded all hospitalizations with ischemic stroke (ICD-10 code I63) as primary discharge diagnosis and the respective hospital admission date. The secondary outcome was hospitalization for any thromboembolic event (TE; alternative terminology: stroke and systemic embolism). TE includes ischemic stroke (I63), transient ischemic attack (G45), peripheral arterial embolism (I74), pulmonary embolism (I26) and mesenterial embolism (K55).

For patients with multiple occurrences of the outcome, only the first was counted, as later re-hospitalizations are often related to the first event. For calculation of person-time at risk, we ended individual follow-up for patients at time of the outcome of interest, death, beginning of treatment with oral anticoagulation, or dropout from the dataset (e.g. due to change of insurance company).

Because of the observational study design, patients might not have received oral anticoagulation due to excessive risk of bleeding. Therefore, we provide estimates of bleeding rates to allow a more detailed assessment of the cohort. We included hospitalizations due to intracranial bleeding (I60, I61, I62, gastrointestinal bleeding (I85.0, I98.3, K25.0, K25.2, K25.4, K25.6, K26.0, K26.2, K26.4, K26.6, K27.0, K27.2, K27.4, K27.6, K28.0, K28.2, K28.4, K28.6, K62.5, K92.2) and acute posthemorrhagic anemia (D62).

\section{Statistical methods}

We calculated incidence rates and 95\%-confidence intervals for primary and secondary outcomes, stratified by the $\mathrm{CHA}_{2} \mathrm{DS}_{2}$-VASc-score. To assess the predictive performance of the risk score, we calculated the concordance index (c-index) of the scores for prediction of ischemic stroke events as area under the curve of corresponding receiver operating characteristic (ROC)-curves [14]. All analyses were done using $R$ (version 3.4.2) [15] and the R package 'pROC' [16].

\section{Sensitivity analysis}

Because the diagnostic certainty of $\mathrm{AF}$ and ischemic stroke rates could be different depending on different health care settings, we calculated incidence rates of ischemic stroke (with 95\%-confidence intervals, stratified by $\mathrm{CHA}_{2} \mathrm{DS}_{2}$-VASc-score) for patients that had a coded diagnosis of AF only from the outpatient setting, only from the inpatient setting, and for those with in- and outpatient diagnosis. In addition, we calculated incidence rates for those with specifically coded diagnosis of permanent atrial fibrillation (I48.2).

\section{Results}

From the total dataset of 3.81 million insured persons, we identified 107,777 patients with nonvalvular AF (approximate prevalence of $2.8 \%$ ) in 2014. Of those, 30,229 patients $(28.0 \%)$ did not receive oral anticoagulation in 2014 (the study population). Their baseline characteristics are summarized in Table 2. For comparison, we also provide in Table 2 baseline characteristics of patients who received at least one prescription of an oral anticoagulant in 2014. Patients with oral anticoagulation have a slightly higher $\mathrm{CHA}_{2} \mathrm{DS}_{2}$-VASc-score and more comorbidities fitting a cardiovascular risk profile (e.g. hypertension, diabetes, vascular disorders).

The primary endpoint (ischemic stroke) occurred in 961 of the 30,299 patients constituting the study population, resulting in an incidence rate of 2.2 per 100 person-years. The secondary endpoint (thromboembolic events) occurred in 1553 patients (3.6 per 100 person-years). Incidence rates with 95\%-confidence intervals for ischemic strokes and thromboembolic events stratified by $\mathrm{CHA}_{2} \mathrm{DS}_{2}$-VASc-score are shown in Table 3. The risk of ischemic stroke and thromboembolism clearly increases with increasing $\mathrm{CHA}_{2} \mathrm{DS}_{2}$-VASc-score and, as judged by $95-\%$ confidence intervals, the score discriminates sufficiently between different levels of risk. The c-index for the primary outcome was 0.608 .

The estimated incidence rate hospitalization due to a bleeding event was 0.83 per 100 person-years (compare Table 3). This rate is low in comparison to published rates from similar studies [7, 17], definitely ruling out an

Table 2 Baseline characteristics of patients with atrial fibrillation with and without oral anticoagulation in 2014

\begin{tabular}{lll}
\hline & $\begin{array}{l}\text { With OAC } \\
(\mathrm{N}=82,331)\end{array}$ & $\begin{array}{l}\text { Without OAC } \\
(\mathrm{N}=30,229)\end{array}$ \\
\hline Age (mean $\pm \mathrm{SD})$ & $77.12 \pm 8.75$ & $76.41 \pm 12.42$ \\
Sex (percent male) & $47.7 \%$ & $46.6 \%$ \\
$\mathrm{CHA}_{2} \mathrm{DS}_{2}$-VASc-score (mean $\left.\pm \mathrm{SD}\right)$ & $4.66 \pm 1.57$ & $4.25 \pm 1.81$ \\
Hypertension & $91.6 \%$ & $85.0 \%$ \\
Chronic heart failure & $47.7 \%$ & $40.2 \%$ \\
Stroke or transient ischemic attack in 2014 & $10.1 \%$ & $7.96 \%$ \\
Stroke in 2014 & $6.4 \%$ & $4.71 \%$ \\
Diabetes mellitus & $44.3 \%$ & $10.1 \%$ \\
Vascular disease & $50.6 \%$ & $12.0 \%$ \\
Alcohol-related disorder & $3.2 \%$ & $5.2 \%$ \\
Dementia & $11.3 \%$ & $19.2 \%$ \\
Anemia & $16.2 \%$ & $19.9 \%$ \\
Renal disease & $32.8 \%$ & $31.90 \%$ \\
Dialysis & $0.9 \%$ & $2.5 \%$ \\
Liver disease & $15.7 \%$ & $15.0 \%$ \\
\hline OAC oral anticoagulation & &
\end{tabular}

$O A C$ oral anticoagulation 
Table 3 Incidence rates of ischemic stroke, thromboembolic events and bleeding events stratified by $\mathrm{CHA}_{2} \mathrm{DS}_{2}-\mathrm{VASc}-\mathrm{score}$ in patients with atrial fibrillation and without oral anticoagulation $(\mathrm{N}=30,229)$

\begin{tabular}{|c|c|c|c|c|c|c|c|c|c|c|c|c|c|}
\hline \multirow{3}{*}{$\begin{array}{l}\mathrm{CHA}_{2} \mathrm{DS}_{2^{-}} \\
\text {VASC } \\
0\end{array}$} & \multirow{3}{*}{$\begin{array}{l}\text { N } \\
721\end{array}$} & \multicolumn{4}{|c|}{ ischemic strokes } & \multicolumn{4}{|c|}{ Thrombembolic events } & \multicolumn{4}{|c|}{ Bleeding } \\
\hline & & \multirow{2}{*}{$\begin{array}{l}\text { events } \\
1\end{array}$} & \multirow{2}{*}{$\begin{array}{l}\begin{array}{l}\text { incidence rate } \\
\text { (per 100py) }\end{array} \\
0.08\end{array}$} & \multicolumn{2}{|c|}{$95 \%-\mathrm{Cl}$} & \multirow{2}{*}{$\begin{array}{l}\text { events } \\
4\end{array}$} & \multirow{2}{*}{$\begin{array}{l}\begin{array}{l}\text { incidence rate } \\
\text { (per 100py) }\end{array} \\
0.31\end{array}$} & \multicolumn{2}{|c|}{$95 \%-\mathrm{Cl}$} & \multirow{2}{*}{$\begin{array}{l}\text { events } \\
2\end{array}$} & \multirow{2}{*}{$\begin{array}{l}\text { incidence rate } \\
\text { (per 100py) } \\
0.15\end{array}$} & \multicolumn{2}{|c|}{$95 \%-\mathrm{Cl}$} \\
\hline & & & & 0.01 & 0.55 & & & 0.12 & 0.82 & & & 0.04 & 0.62 \\
\hline 1 & 1881 & 16 & 0.48 & 0.30 & 0.79 & 26 & 0.79 & 0.54 & 1.16 & 11 & 0.33 & 0.19 & 0.60 \\
\hline 2 & 2636 & 47 & 1.08 & 0.82 & 1.44 & 83 & 1.92 & 1.55 & 2.37 & 21 & 0.48 & 0.32 & 0.74 \\
\hline 3 & 4208 & 85 & 1.30 & 1.05 & 1.60 & 137 & 2.10 & 1.78 & 2.47 & 34 & 0.52 & 0.37 & 0.72 \\
\hline 4 & 6394 & 215 & 2.31 & 2.02 & 2.63 & 332 & 3.58 & 3.22 & 3.98 & 84 & 0.90 & 0.73 & 1.11 \\
\hline 5 & 6784 & 243 & 2.58 & 2.28 & 2.93 & 390 & 4.18 & 3.79 & 4.60 & 87 & 0.92 & 0.75 & 1.14 \\
\hline 6 & 4823 & 200 & 3.27 & 2.86 & 3.75 & 341 & 5.62 & 5.07 & 6.24 & 78 & 1.28 & 1.02 & 1.59 \\
\hline 7 & 2066 & 107 & 4.18 & 3.47 & 5.04 & 164 & 6.44 & 5.55 & 7.46 & 31 & 1.21 & 0.85 & 1.71 \\
\hline 8 & 530 & 33 & 5.31 & 3.81 & 7.39 & 53 & 8.58 & 6.64 & 11.10 & 10 & 1.59 & 0.86 & 2.93 \\
\hline 9 & 186 & 14 & 7.22 & 4.36 & 11.96 & 23 & 12.27 & 8.37 & 18.0 & 4 & 2.03 & 0.77 & 5.35 \\
\hline Total & 30,229 & 961 & 2.20 & 2.07 & 2.34 & 1553 & 3.55 & 3.38 & 3.73 & 362 & 0.83 & 0.75 & 0.92 \\
\hline
\end{tabular}

Thromboembolic events include ischemic stroke, transient ischemic attack, peripheral arterial embolism, pulmonary embolism, and mesenterial embolism Bleeding events include intracranial bleeding, gastrointestinal bleeding and acute posthemorrhagic anemia

$\mathrm{Cl}$ confidence interval, py person-years

excessive bleeding risk, on average, in this study's cohort.

A comparison of estimated incidence rates with those reported in the literature is shown in Table 4 and Fig. 1. Ischemic stroke rates stratified by the $\mathrm{CHA}_{2} \mathrm{DS}_{2^{--}}$ VASc-score are lower than those reported by Friberg [7], van den Ham [8], Kim [9] and Allan [12]. Thromboembolic event rates stratified by $\mathrm{CHA}_{2} \mathrm{DS}_{2--}$ VASc-score approximately fall between those reported by Olesen [11] and Singer [10]. Especially with higher $\mathrm{CHA}_{2} \mathrm{DS}_{2}$-VASc-scores $(\geq 5)$, estimates from this study are considerably lower. However, there is large variability in reported rates.
The results of the sensitivity analysis (Table 5) show a trend towards higher incidence rates for those patients with in- and outpatient diagnoses of AF and those with permanent AF, albeit with largely overlapping $95 \%$-confidence intervals.

\section{Discussion}

\section{Key results}

Our results show that incidence rates of ischemic stroke in uncoagulated patients with AF are lower in Germany compared to internationally reported incidence rates.

Most of those studies report either rates of ischemic strokes or rates of thromboembolic events (including

Table 4 Comparison of reported incidence rates of ischemic stroke (IS) and thromboembolic events (TE) stratified by $\mathrm{CHA}_{2} \mathrm{DS}_{2}-$

\begin{tabular}{|c|c|c|c|c|c|c|c|c|c|c|}
\hline \multirow{2}{*}{$\begin{array}{l}\mathrm{CHA}_{2} \mathrm{DS}_{2}- \\
\text { VASc }\end{array}$} & \multicolumn{2}{|c|}{ Wicke et al. } & \multirow{2}{*}{$\begin{array}{l}\text { Lip (6) } \\
\text { TE }\end{array}$} & \multicolumn{2}{|c|}{ Friberg (7) } & \multirow{2}{*}{$\begin{array}{l}\text { van den Ham (8) } \\
\text { IS }\end{array}$} & \multirow{2}{*}{$\begin{array}{l}\text { Kim (9) } \\
\text { IS }\end{array}$} & \multirow{2}{*}{$\begin{array}{l}\text { Singer (10) } \\
\text { TE }\end{array}$} & \multirow{2}{*}{$\begin{array}{l}\text { Olesen (11) } \\
\text { TE }\end{array}$} & \multirow{2}{*}{$\begin{array}{l}\text { Allan (12 } \\
\text { IS }\end{array}$} \\
\hline & IS & TE & & IS & $\mathrm{TE}$ & & & & & \\
\hline 0 & 0.1 & 0.3 & 0 & 0.2 & 0.3 & 0.4 & 0.2 & 0.0 & 0.7 & 0.2 \\
\hline 1 & 0.5 & 0.8 & 0.6 & 0.6 & 0.9 & 0.8 & 1.0 & 0.6 & 1.5 & 0.7 \\
\hline 2 & 1.1 & 1.9 & 1.6 & 2.2 & 2.9 & 1.9 & 1.9 & 0.8 & 2.9 & 1.4 \\
\hline 3 & 1.3 & 2.1 & 3.9 & 3.2 & 4.6 & 2.8 & 2.5 & 1.7 & 4.3 & 2.6 \\
\hline 4 & 2.3 & 3.6 & 1.9 & 4.8 & 6.7 & 3.7 & 4.7 & 2.8 & 6.5 & 4.0 \\
\hline 5 & 2.6 & 4.2 & 3.2 & 7.2 & 10 & 5.1 & 5.8 & 4.3 & 10.0 & 6.2 \\
\hline 6 & 3.3 & 5.6 & 3.6 & 9.7 & 13.6 & 7.1 & 8.4 & 4.8 & 12.5 & 12.1 \\
\hline 7 & 4.2 & 6.4 & 8.0 & 11.2 & 15.7 & 9.0 & 8.8 & 4.8 & 14.0 & 14.5 \\
\hline 8 & 5.3 & 8.6 & 11.1 & 10.8 & 15.2 & 9.0 & & 7.8 & 14.1 & 17.6 \\
\hline 9 & 7.2 & 12.3 & 100 & 12.2 & 17.4 & 15.5 & & 16.6 & 15.9 & 24.3 \\
\hline Total & 2.2 & 3.6 & $\sim 2.4^{\mathrm{a}}$ & 4.5 & 6.2 & 2.9 & 4.0 & 2.1 & $\mathrm{n} / \mathrm{a}^{\mathrm{b}}$ & 3.8 \\
\hline
\end{tabular}

\footnotetext{
aTotal incidence rate not given in original publication, but approximated from given data
}

${ }^{\mathrm{b}}$ Total incidence rate not available from original publication 


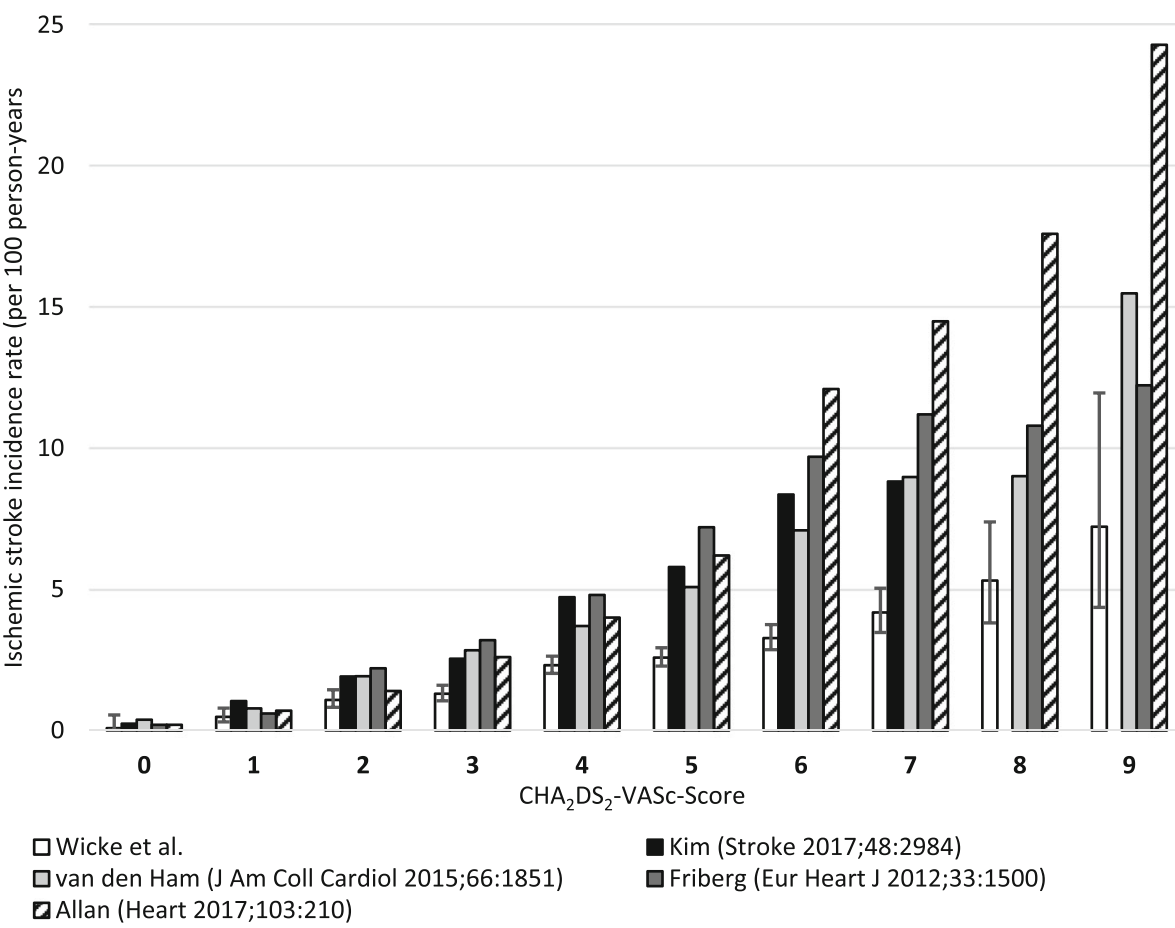

Fig. 1 Comparison of ischemic stroke incidence rates in patients with atrial fibrillation and without oral anticoagulation (whiskers show 95\%-confidence intervals)

peripheral arterial embolism and pulmonary embolism in addition to cerebral ischemia). This limits comparability of results. We believe that ischemic stroke is the most relevant outcome, as it is clearly linked to AF. We agree with Friberg et al. [18] that transient ischemic attack, which by definition has a benign outcome, is not a good outcome for studying stroke risk in this context. The rationale for including pulmonary embolism as an outcome is that it is potentially preventable by oral anticoagulation. Whether AF itself is a relevant causative risk factor for pulmonary embolism is under debate [19-22], but in general, pulmonary emboli are thought to arise mainly from thrombosis in the lower extremities [23]. We decided to use ischemic strokes as primary outcome and report thromboembolic events as secondary outcome.

Incidence rate estimates for ischemic strokes from this study are lower than previously reported estimates, but

Table 5 Sensitivity analysis showing ischemic stroke incidence rates stratified by $\mathrm{CHA}_{2} \mathrm{DS}_{2}$-VASc-score for those patients with coded diagnoses of atrial fibrillation only from the outpatient, only from inpatient and in- \& outpatient settings

\begin{tabular}{|c|c|c|c|c|}
\hline \multirow{2}{*}{$\begin{array}{l}\mathrm{CHA}_{2} \mathrm{DS}_{2^{-}} \\
\text {VASC }\end{array}$} & \multicolumn{4}{|c|}{ ischemic stroke incidence rates (per 100 person-years) [95\%-confidence intervals] } \\
\hline & $\begin{array}{l}\text { outpatient diagnosis } \\
N=18,915\end{array}$ & $\begin{array}{l}\text { inpatient diagnosis } \\
N=6887\end{array}$ & $\begin{array}{l}\text { in- and outpatient diagnosis } \\
N=4427\end{array}$ & $\begin{array}{l}\text { only permanent atrial fibrillation } \\
\text { (ICD-10: } 148.2 \text { ) } \\
N=5033\end{array}$ \\
\hline 0 & $0.11[0.02-0.76]$ & 0 & 0 & 0 \\
\hline 1 & $0.44[0.24-0.79]$ & $0.82[0.31-2.16]$ & $0.35[0.05-2.47]$ & $1.47[0.48-4.51$ \\
\hline 2 & $1.18[0.86-1.61]$ & $0.57[0.22-1.52]$ & $1.25[0.47-3.32]$ & $0.94[0.31-2.91]$ \\
\hline 3 & $1.24[0.97-1.59]$ & $1.61[1.02-2.55]$ & $1.15[0.52-2.55]$ & $1.87[1.11-3.13]$ \\
\hline 4 & $2.26[1.93-2.65]$ & $2.26[1.66-3.06]$ & $2.70[1.85-3.95]$ & $3.83[2.90-5.06]$ \\
\hline 5 & $2.39[2.03-2.81]$ & $2.39[1.83-3.13]$ & $3.80[2.89-5.01]$ & $2.84[2.13-3.77]$ \\
\hline 6 & $2.67[2.17-3.28]$ & $3.50[2.72-4.51]$ & $4.69[3.61-6.08]$ & $3.99[3.04-3.77]$ \\
\hline 7 & 3.68 [2.75-4.92] & $3.99[2.84-5.60]$ & $5.54[3.94-7.80]$ & $5.25[3.70-7.43]$ \\
\hline 8 & $4.86[2.73-8.65]$ & $4.25[2.32-7.80]$ & 7.48 [4.34-12.89] & $5.47[2.79-10.74]$ \\
\hline 9 & $5.38[2.08-13.96]$ & $8.07[3.48-18.71]$ & $8.67[3.74-20.05]$ & $6.63[2.57-17.08]$ \\
\hline
\end{tabular}


those for thromboembolic events are within the range of previous studies. This suggests the possibility that the outcomes stroke and thromboembolic events might be detected or recorded differently in different health-care settings (e.g. stroke as transient ischemic attack). We suggest that studies on the topic should optimally report both outcomes.

There are multiple methodological challenges in estimating risks in patients with AF: RCTs have shown the overall advantage of anticoagulation, but have been not been powered or designed in regard to risk-benefit stratification based on baseline characteristics, which are required for individual clinical decision making. Therefore risk estimation relies on observational studies of patients with and without anticoagulation, which suffers from potential confounding by indication [24], that is, patients actually receiving anticoagulation are possibly (and likely) different in key characteristics related to ischemic stroke and bleeding risks from those that do not receive anticoagulation. These differences can result from physician's or patient's decisions for or against anticoagulation and may be based on false beliefs regarding oral anticoagulants (e.g. overestimating the risk of falling or underestimating benefits of anticoagulation in elderly patients).

\section{Limitations}

Confounding by indication is a possible source of bias in this study and our data does not contain information on the specific reasons for or against anticoagulation in the cohort. One aspect of confounding by indication is bleeding risk, either objective or subjective fear of bleeding by either patient or physician, which could account for the decision against oral anticoagulation. Bleeding incidence for this study's cohort, however, are not excessive (Table 3) and we thus conclude that objective bleeding risk is not a major confounding factor.

Further limitations of the study are the potential for exposure, covariate and outcome misclassification inherent to secondary data analysis. Exposure misclassification regarding $\mathrm{AF}$ is possible, as we rely on the validity of coded diagnoses and had no possibility of electrocardiogram-based verification. We included codes for paroxysmal and persistent $\mathrm{AF}$ and for atrial flutter, because all diagnoses are indications for oral anticoagulation [3]. The prevalence estimate of AF in our study is slightly higher than previous results from Germany: $2.5 \%$ was reported from the Gutenberg-Health Study [25] and Wilke et al. [26] reported 2.1\% (but they included persistent AF, only). To increase validity of AF diagnoses, we required a diagnostic code from two different quarters in the baseline year 2014. Additionally we conducted a sensitivity analysis, to check whether incidence rates of ischemic strokes differ for patients with
AF diagnoses exclusively from the outpatient, inpatient and in- and outpatient setting (Table 5). This analysis shows a trend towards higher incidence rates for patients with diagnostic codes from the in- and outpatient setting. Possible explanations are that there is some degree of overcoding (e.g. false-positive diagnoses) or that the trend reflects the higher risk of patients that were previously hospitalized, but the sensitivity analysis does not explain the overall comparatively low incidence rates. Also, inclusion of unspecific and paroxysmal AF does not seem to explain the comparatively low ischemic stroke rates, as estimates for the subgroup with permanent AF largely overlap with the total cohort (Table 5).

Covariates, specifically comorbidities used for the calculation of the $\mathrm{CHA}_{2} \mathrm{DS}_{2}$-VASc-score, were assessed based on the year 2014 only. Therefore, it is possible that existing conditions, like a stroke or transient ischemic attack that occurred in the years before, could be missed in the calculation of the score. This would result in an underestimation of the true score and in turn to an overestimation of stroke risk in the corresponding score group.

Germany has a well-established acute care system for stroke, including nearly universal access to specialized stroke units. The vast majority of hospitalized patients with suspected stroke receive neuroimaging. We therefore consider the validity of the primary outcome as high. The ICD-10, however, does not allow coding of the exact etiology of embolic strokes. The primary outcome thus includes cases of non-cardioembolic ischemic strokes (e.g. embolism from aortic, cervical or cranial plaques or microangiopathic ischemia), which is a relevant concern in studies of risk estimation in AF, because the preventive treatment of choice for atherosclerotic thromboembolism is thrombocyte aggregation inhibition. We could not account for ischemic strokes that did not lead to hospital admission, e.g. because patients died or did not seek care.

Estimates for those with low risk of events and sensitivity analyses are limited by relatively wide confidence intervals, despite the relatively large cohort size.

\section{Interpretation}

Our results suggest that ischemic stroke incidence rates are lower for the observed population from southern Germany in comparison to internationally reported rates. In addition to the limitations discussed above, we give possible explanations for this observation.

Risk compositions are likely to be different in AF cohorts sampled from hospital registries or specialist care and those sampled from primary care or the general population, as was shown by Allan et al. [12] for patients from Great Britain. Friberg et al. [7] used data from a Swedish hospital discharge registry, which might not be 
representative for primary care or the general population. Kim et al. [9] used data from the Korean National Health Insurance, but risks are probably different in Korean and European populations.

The risk of ischemic stroke might change over time. Our recent data (2015 and 2016) could reflect those trends in comparison to previous studies, which used data sources going back into the 1990s and epidemiological studies show a trend toward declining overall ischemic stroke incidence rates [27]. This could be part of the explanation for the comparatively low rates observed in this study. Increased awareness of physicians and patients of AF could lead to earlier detection, at a stage where risk of thromboembolism might be lower. Detection rates could furthermore be different depending on characteristics of the health care system (e.g. number of physician visits or health "check-ups"), which in turn could influence the risk composition. Also, optimized treatment of comorbidities might lower the relative risk associated with each specific comorbidity used for calculation of the $\mathrm{CHA}_{2} \mathrm{DS}_{2}$-VASc-score.

Geographic variation in anticoagulation treatment could change the risk composition of the uncoagulated populations. Wide geographic variation in oral anticoagulation has been observed $[28,29]$. In regions with high coverage of oral anticoagulation, this would leave a relatively low risk composition in the uncoagulated population and vice versa.

We reported incidence rates based on the first event occurring in each patient, because additional hospitalizations have a high likelihood of being related to the first. However, this does not need to be the case and a different approach would be to count further events for the calculation of incidence rates (optimally with a latency period between events). This, of course, would result in higher incidence rate estimates. Unfortunately, most published studies do not specify how they treated multiple events, which limits comparability.

\section{Generalizability}

In Germany, statutory health insurance covers about $90 \%$ of the population; most of the remainder are high-income and privately insured patients. Overall, we consider the cohort therefore as fairly representative of the patient population in German practices and hospitals.

\section{Conclusion}

Our results suggest that the performance of the $\mathrm{CHA}_{2} \mathrm{DS}_{2}$-VASc-score differs in the German population compared to internationally published data, with an overall trend towards lower risk of ischemic stroke in uncoagulated patients with AF. Because of the diverse methodological challenges these results should at this stage not yet be practice changing. Rather we believe that stroke risk estimation in patients with atrial fibrillation should be further refined. This could be done with epidemiological studies ideally taking into account factors more specific to individual risk (e.g. echocardiography [30, 31] and biomarkers [32]) and with specific outcome assessment (only counting ischemia likely to be of cardioembolic origin).

\section{Abbreviations \\ AF: Atrial fibrillation; ATC: Anatomical-therapeutic-chemical classification; \\ Cl: Confidence interval; C-Index: Concordance index; ICD-10: International classification of disease, version 10; OAC: Oral anticoagulation; \\ RCT: Randomized and controlled trial; ROC: Receiver operating characteristic; TE: Thromboembolic event}

\section{Acknowledgements}

The authors thank the AOK Baden-Wuerttemberg for providing data for the project and the aQua-Insitute (Göttingen, Germany) for participating in data preparation. We thank Janet C. Harvey for English language editing.

\section{Funding}

The Innovation Fund of the Federal Joint Committee (Gemeinsamer Bundesausschuss) of the Federal Republic of Germany funds the project (No, 01VSF16003). The funding source had no role in the design, conduct, analysis, and reporting of the study.

\section{Availability of data and materials}

Due to legislation of the German social code (book V) regulating statutory health insurance issues, we are not allowed to provide data from this study.

\section{Authors' contributions}

FW, KK and MB contributed in design of the study, data interpretation, and manuscript editing. FW prepared and analyzed the data and wrote the initial draft. BM and MS contributed in data interpretation and critical revisions of the manuscript. All authors read and approved the final manuscript.

\section{Ethics approval and consent to participate}

This study is part of a project evaluating cardiovascular health care in the German State of Baden-Wuerttemberg and was approved by the ethics committee of the Faculty of Medicine of the Goethe-University Frankfurt (Main), Germany (reference number 291/17). We obtained no individual consent of participants, because anonymized secondary data were used.

Consent for publication

Not applicable.

\section{Competing interests}

The authors declare that they have no competing interests.

\section{Publisher's Note}

Springer Nature remains neutral with regard to jurisdictional claims in published maps and institutional affiliations.

\section{Author details}

${ }^{1}$ Institute of General Practice, Goethe-University, Theodor-Stern-Kai 7, 60590 Frankfurt, Germany. ${ }^{2}$ Department of Neurology, Goethe-University,

Schleusenweg 2-16, 60528 Frankfurt, Germany.

Received: 26 November 2018 Accepted: 9 April 2019

Published online: 23 April 2019

References

1. Hart RG, Pearce LA, Aguilar MI. Meta-analysis: antithrombotic therapy to prevent stroke in patients who have nonvalvular atrial fibrillation. Ann Intern Med. 2007;146(12):857-67. 
2. Aguilar MI, Hart R. Oral anticoagulants for preventing stroke in patients with non-valvular atrial fibrillation and no previous history of stroke or transient ischemic attacks. Cochrane Database Syst Rev 2005; (3):CD001927.

3. Kirchhof P, Benussi S, Kotecha D, Ahlsson A, Atar D, Casadei B, et al. 2016 ESC guidelines for the management of atrial fibrillation developed in collaboration with EACTS. Eur Heart J. 2016:37(38):2893-962.

4. January CT, Wann LS, Alpert JS, Calkins H, Cigarroa JE, Cleveland JC, et al. 2014 AHA/ACC/HRS guideline for the management of patients with atrial fibrillation: a report of the American College of Cardiology/American Heart Association task force on practice guidelines and the Heart Rhythm Society. Circulation. 2014;130(23):e199-267.

5. January CT, Wann LS, Calkins H, Chen LY, Cigarroa JE, Cleveland JC, et al. 2019 AHA/ACC/HRS focused update of the 2014 AHA/ACC/HRS guideline for the Management of Patients with Atrial Fibrillation. Circulation. 2019: CIR0000000000000665.

6. Lip GYH, Nieuwlaat R, Pisters R, Lane DA, Crijns HJGM. Refining clinical risk stratification for predicting stroke and thromboembolism in atrial fibrillation using a novel risk factor-based approach: the euro heart survey on atrial fibrillation. Chest. 2010;137(2):263-72.

7. Friberg L, Rosenqvist M, Lip GYH. Evaluation of risk stratification schemes for ischaemic stroke and bleeding in 182678 patients with atrial fibrillation: the Swedish atrial fibrillation cohort study. Eur Heart J. 2012;33(12):1500-10.

8. van den Ham HA, Klungel OH, Singer DE, Leufkens HGM, van Staa TP. Comparative performance of ATRIA, CHADS2, and CHA2DS2-VASC risk scores predicting stroke in patients with atrial fibrillation. Results From a National Primary Care Database J Am Coll Cardiol. 2015;66(17):1851-9.

9. Kim T-H, Yang P-S, Kim D, Yu HT, Uhm J-S, Kim J-Y, et al. CHA2DS2-VASC score for identifying truly low-risk atrial fibrillation for stroke: a Korean Nationwide cohort study. Stroke. 2017;48(11):2984-90.

10. Singer DE, Chang Y, Borowsky LH, Fang MC, Pomernacki NK, Udaltsova N, et al. A new risk scheme to predict ischemic stroke and other thromboembolism in atrial fibrillation: the ATRIA study stroke risk score. J Am Heart Assoc. 2013;2(3):e000250.

11. Olesen JB, Lip GYH, Hansen ML, Hansen PR, Tolstrup JS, Lindhardsen J, et al. Validation of risk stratification schemes for predicting stroke and thromboembolism in patients with atrial fibrillation: Nationwide cohort study. BMJ. 2011;342:d124.

12. Allan V, Banerjee A, Shah AD, Patel R, Denaxas S, Casas J-P et al. Net clinical benefit of warfarin in individuals with atrial fibrillation across stroke risk and across primary and secondary care. Heart 2017; 103(3):210-218. Available from: URL: https://heart.bmj.com/content/103/3/210.

13. Quinn GR, Severdija ON, Chang Y, Singer DE. Wide variation in reported rates of stroke across cohorts of patients with atrial fibrillation. Circulation. 2017;135(3):208-19.

14. Zhou X-H, Obuchowski NA, McClish DK. Statistical methods in diagnostic medicine. 2., Auflage. New York, NY: John Wiley \& Sons; 2011. (Wiley Series in Probability and Statistics).

15. R Core Team. R: A language and environment for statistical computing. Vienna, Austria; 2017. Available from: URL: https://www.R-project.org/.

16. Robin X, Turck N, Hainard A, Tiberti N, Lisacek F, Sanchez J-C, et al. pROC: an open-source package for $\mathrm{R}$ and $\mathrm{S}+$ to analyze and compare ROC curves. BMC Bioinformatics. 2011;12:77

17. Pisters R, Lane DA, Nieuwlaat R, de VCB, Crijns HJGM, Lip GYH. A novel userfriendly score (HAS-BLED) to assess 1-year risk of major bleeding in patients with atrial fibrillation: the euro heart survey. Chest. 2010;138(5):1093-100.

18. Friberg L, Skeppholm M, Terént A. Benefit of anticoagulation unlikely in patients with atrial fibrillation and a CHA2DS2-VASc score of 1. J Am Coll Cardiol. 2015;65(3):225-32.

19. Bikdeli B, Abou Ziki MD, Lip GYH. Pulmonary embolism and atrial fibrillation: two sides of the same coin? A systematic review. Semin Thromb Hemost. 2017:43(8):849-63.

20. Flegel KM. When atrial fibrillation occurs with pulmonary embolism, is it the chicken or the egg? vol. 160; 1999. p. 1181-2.

21. Ogren M, Bergqvist D, Eriksson H, Lindblad B, Sternby NH. Prevalence and risk of pulmonary embolism in patients with intracardiac thrombosis: a population-based study of 23796 consecutive autopsies. Eur Heart J. 2005; 26(11):1108-14.

22. van Langevelde K, Srámek A, Vincken PWJ, van Rooden J-K, Rosendaal FR, Cannegieter SC. Finding the origin of pulmonary emboli with a total-body magnetic resonance direct thrombus imaging technique. Haematologica. 2013;98(2):309-15.
23. Di Nisio M, van Es N, Büller HR. Deep vein thrombosis and pulmonary embolism. Lancet. 2016:388(10063):3060-73.

24. Catalogue of bias collaboration, Aronson JK, Bankhead C, Mahtani KR, Nunan D. Confounding by indication. Calaogue Of Biases; 2018 [cited 2018 Nov 13]. Available from: URL: https://catalogofbias.org/biases/confoundingby-indication.

25. Schnabel RB, Wilde S, Wild PS, Munzel T, Blankenberg S. Atrial fibrillation: its prevalence and risk factor profile in the German general population. Dtsch Arztebl Int. 2012;109(16):293-9.

26. Wilke T, Groth A, Mueller S, Pfannkuche M, Verheyen F, Linder R, et al. Incidence and prevalence of atrial fibrillation: an analysis based on 8.3 million patients. Europace. 2013;15(4):486-93.

27. Asinger RW, Shroff GR, Simegn MA, Herzog CA. Anticoagulation for Nonvalvular atrial fibrillation: influence of epidemiologic trends and clinical practice patterns on risk stratification and net clinical benefit. Circ Cardiovasc Qual Outcomes. 2017;10(9).

28. Hernandez I, Saba S, Zhang Y. Geographic variation in the use of oral anticoagulation therapy in stroke prevention in atrial fibrillation. Stroke. 2017:48(8):2289-91.

29. Steinberg BA, Gao H, Shrader P, Pieper K, Thomas L, Camm AJ, et al. International trends in clinical characteristics and oral anticoagulation treatment for patients with atrial fibrillation: results from the GARFIELD-AF, ORBIT-AF I, and ORBIT-AF II registries. Am Heart J. 2017;194:132-40.

30. Atrial Fibrillation Investigators. Predictors of thromboembolism in atrial fibrillation: II. Echocardiographic features of patients at risk. The stroke prevention in atrial fibrillation Investigators. Ann Intern Med. 1992;116(1):612.

31. Atrial Fibrillation Investigators. Echocardiographic predictors of stroke in patients with atrial fibrillation: a prospective study of 1066 patients from 3 clinical trials. Arch Intern Med. 1998;158(12):1316-20.

32. Hijazi Z, Oldgren J, Siegbahn A, Granger CB, Wallentin L. Biomarkers in atrial fibrillation: a clinical review. Eur Heart J. 2013;34(20):1475-80.

Ready to submit your research? Choose BMC and benefit from:

- fast, convenient online submission

- thorough peer review by experienced researchers in your field

- rapid publication on acceptance

- support for research data, including large and complex data types

- gold Open Access which fosters wider collaboration and increased citations

- maximum visibility for your research: over $100 \mathrm{M}$ website views per year

At $\mathrm{BMC}$, research is always in progress.

Learn more biomedcentral.com/submissions 